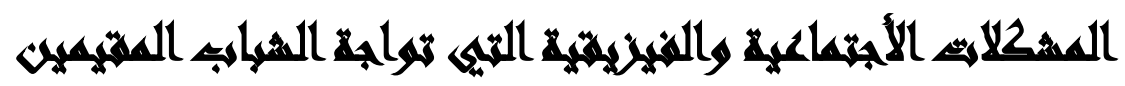

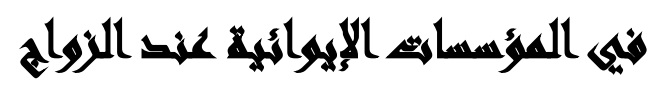

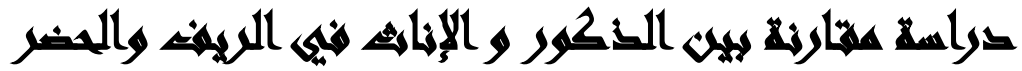

[Ir]

( ) معهد الدراسات عبد المنعم أحمد (')- أحمد فخري هاني (')- ضحي سامي علي إبراهيم

ll

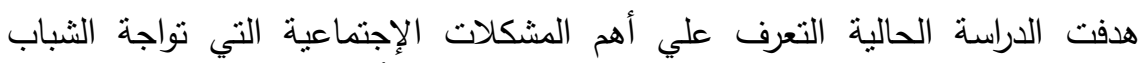

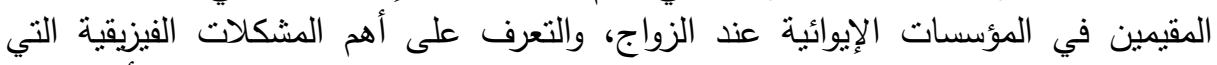

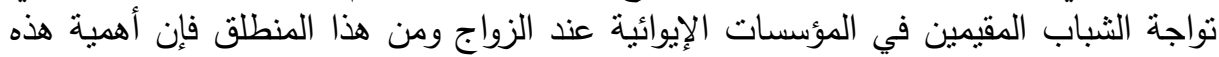

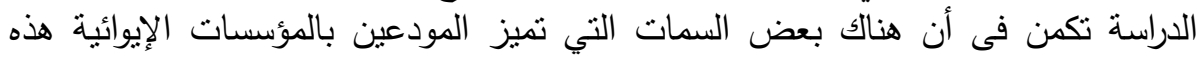

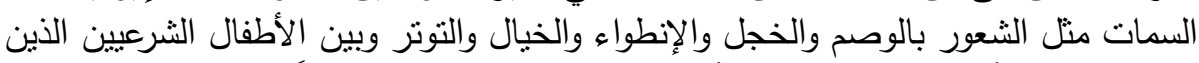

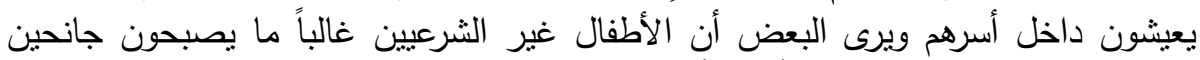

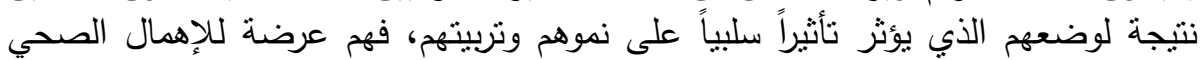

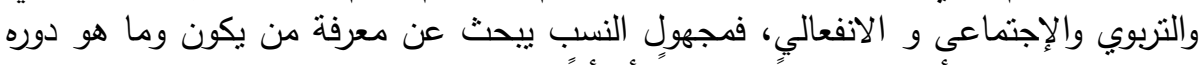

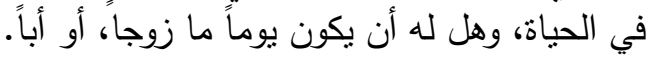

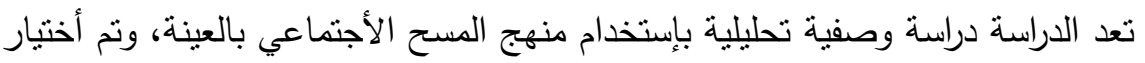

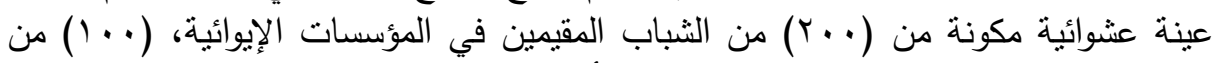

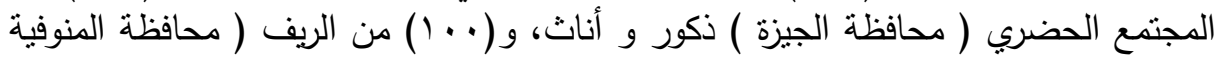

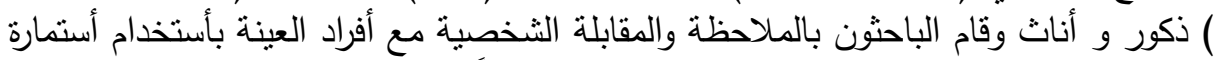

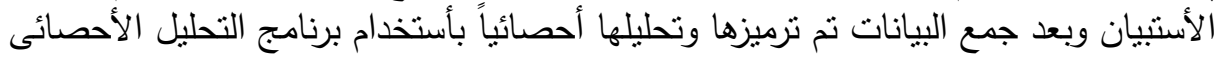

.SPSS

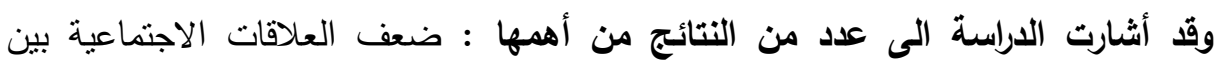

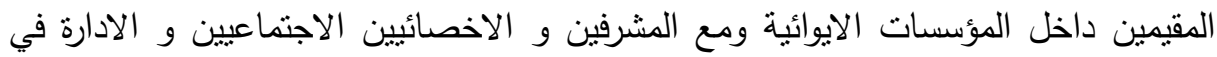

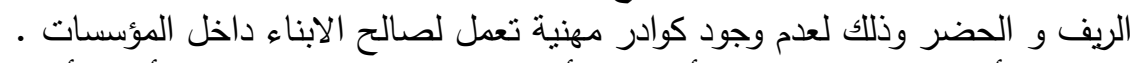

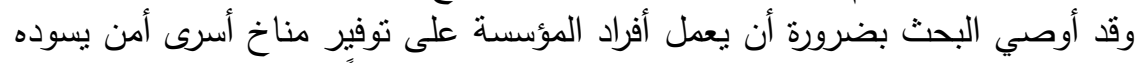

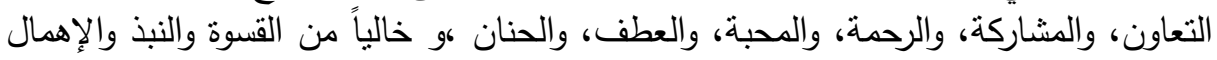

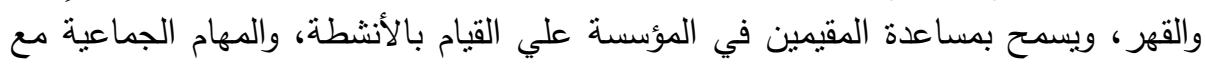


أصدقائهم، حتى يتاح لهم فرص التفاعل الجيد معهم، وكذلك توفير جو من المساندة

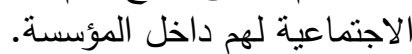

\section{ramid}

تعتبر الأسرة هي الخلية الأولى للحباة الأجتماعية وهى أولى الجماعات التي يحتلك بها

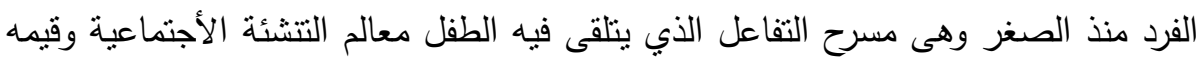
وعاداته وتقاليده بحيث تخلق فيه كائناً إجتماعياً وهى التي تعلم الفرد الأساليب السلوكية

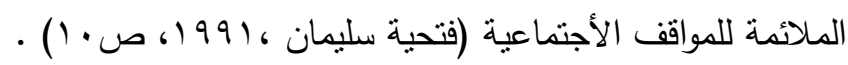

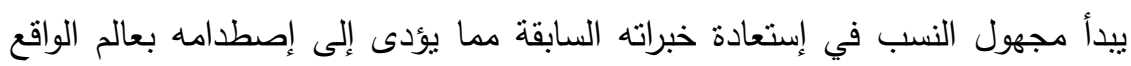

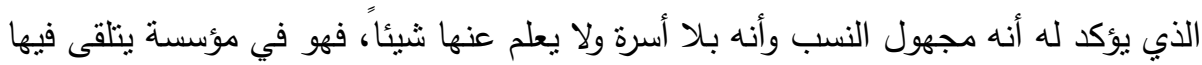

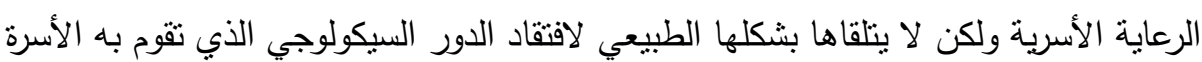

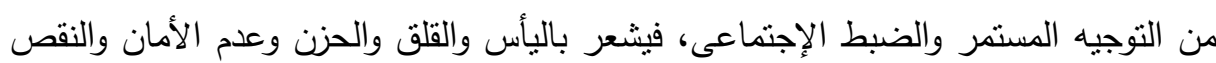

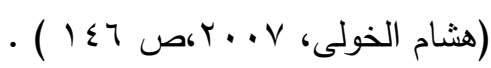

لذا وجب عمل دراسة مستقيضة عن المشكلات الأجتماعية و الفيزيقية التي تواجه الثباب مجهولي النسب داخل المؤسسات الايوائية، وهي دراسة مقارنة ما بين الذكور و الأناث

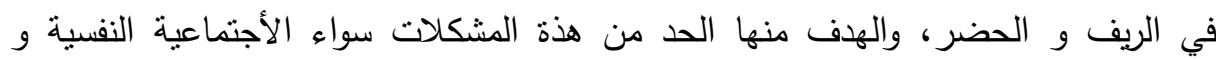
الفيزيقية التي تواجة هؤلاء الثباب داخل المؤسسات.

\section{And}

من أهم الفئات التي حرمت من رعاية الأسرة والحياة الطبيعية هي فئة مجهولى النسب

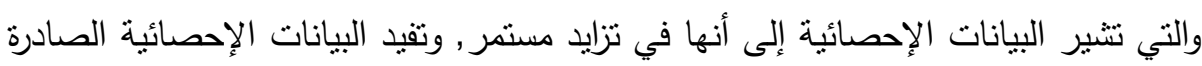

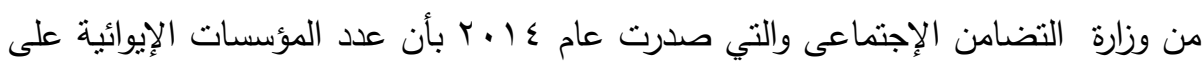

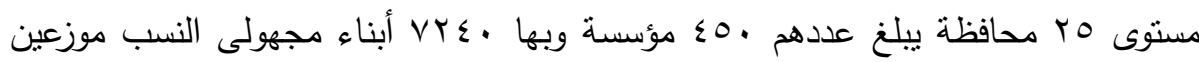

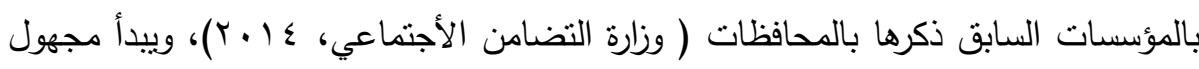

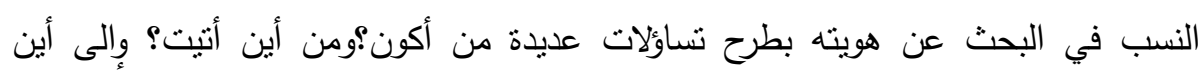
260

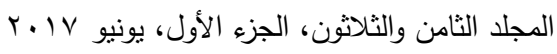


أمضى؟ وإلى أى طريق أكون؟ ويبدأ بالبحث عن كينونته، وعن هويته وعندما يفتل في تحديد

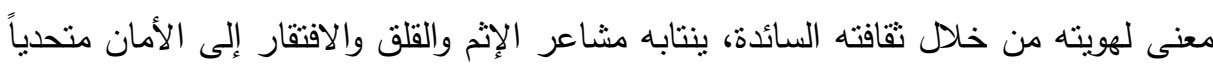

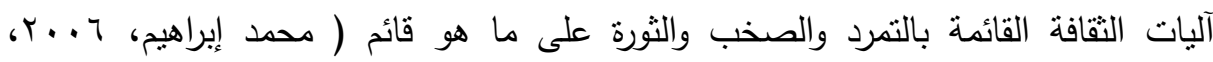

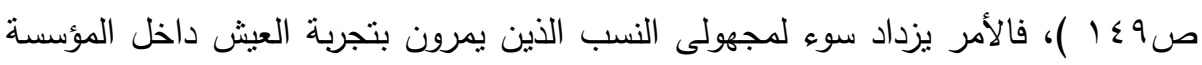

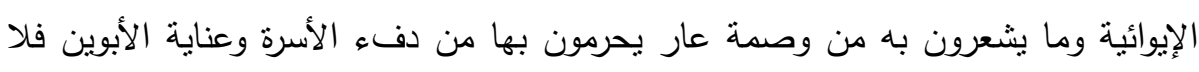

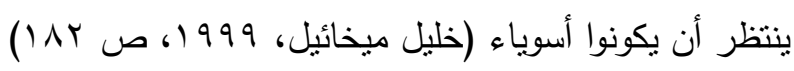

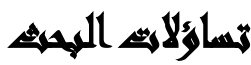

-ما أهم المشكلات الإجتماعية التي تواجه الثباب المقيمين في المؤسسات الإيوائية عند

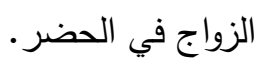

- ما أهم المشكلات الإجتماعية الني تواجة الثباب المقيمين في المؤسسات الإيوائية عند

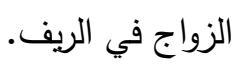

- ما أهم المشكلات الفيزيقية التي تواجة الثباب المقيمين في المؤسسات الإيوائية عند الزواج

$$
\text { في الحضر. }
$$

- ما أهم المشكلات الفيزيقية التي تواجة الثباب المقيمين في المؤسسات الإيوائية عند الزواج في الريف.

\section{أهمبر المهمه}

تكمن أهمية الدراسة في أن هناك بعض السمات التي تميز المودعين بالمؤسسات الإيوائية هذه السمات متل الشعور بالوصم والخجل والانطواء والخيال والتوتر وبين الأطفال

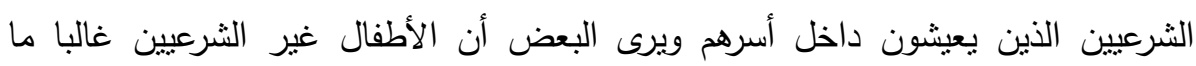

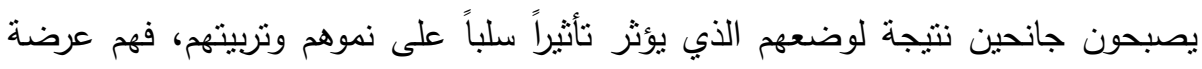

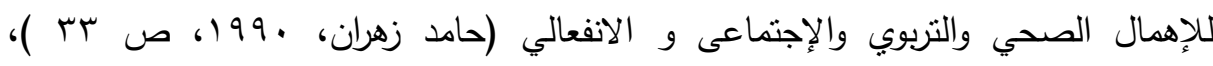

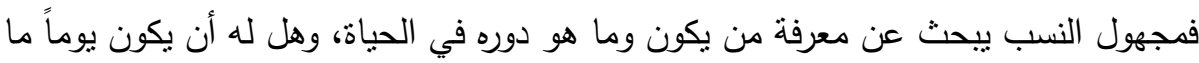

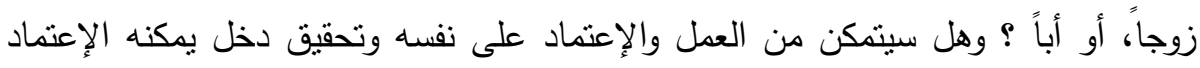

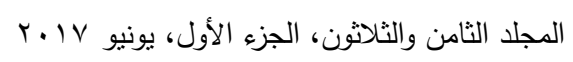


عليه؟ وهل سيشعر بتقته في نفسه حتى لو كانت سماته لا ترضى بعضاً من الناس وهل

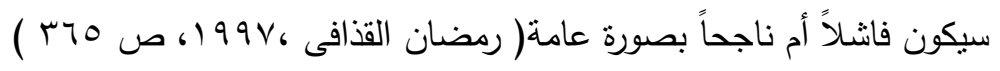
لذللك تسعي هذة الدراسة للكثف عن أهم المشكلات الإجتماعية والفيزيقية التي تواجة التهات

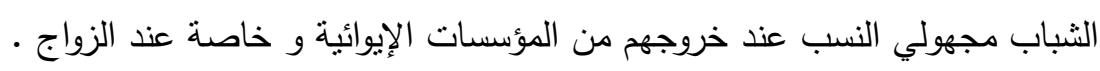

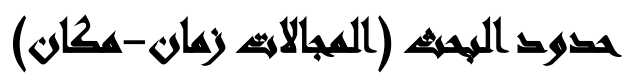

المجال الزمني: نم إجراء البحث الميداني خلال شهرى يناير و فبراير عام V I. r. المجال الجغرافي: فى محافظة الجيزة و محافظة المنوفية .

\section{أهما اهنه المهمث}

ا. التعرف علي أهم المشكلات الإجتماعية التي تواجة الثباب المقيمين في المؤسسات

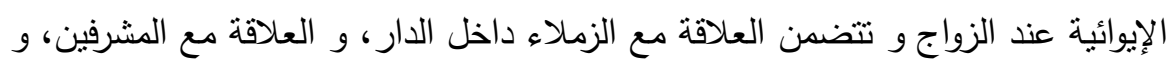

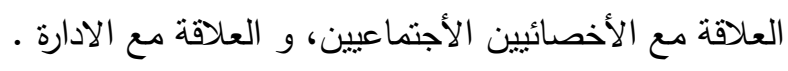
r. التعرف على أهم المشكلات الفيزيقية التي تواجة الثباب المقيمين في المؤسسات الإدينة الإيوائية

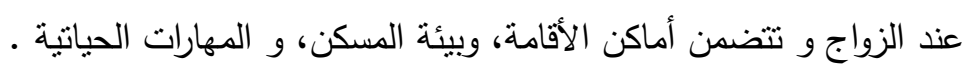

\section{1المهاهيم:}

المشكلات الاجتماعية: Social problems: هي المفارقات ما بين المستويات المرغوبة و الظروف الواقعية فهي مشكلات بمعني أنها تمنل أضطراباً وتعطلاً لسير الأمور

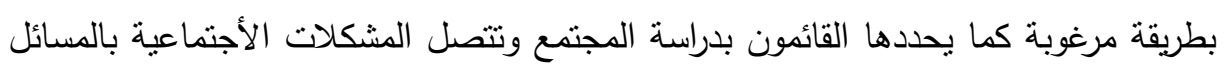

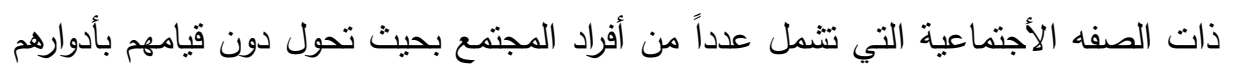
الأجتماعية وأخيراً هي حاله أو ظروف بين الناس وبيئاتهم تؤدي الي أستجابات أجنماعية فهي لئي طرق تقييم الناس ومعاييرهم وتؤدي الي معاناة عاطفية أو أقتصادية ومثال لهذة المشاكل 
(الجريمه، الأنحراف الأجتماعي، اللامساواه الأجتماعية، الفقر، العنصرية، إساءه استخدام

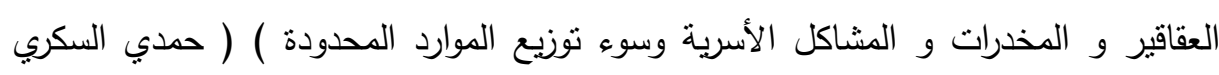
. ( $\Sigma q \wedge$ ص ص....

المشكلات الفيزيقية (البيئية): Physical problems: تعرف الشكلات البيئية من منظور بيئي بأنها حدوث خلل أو تدهور في علاقة مصفوفة عناصر النظام البيئي، وما

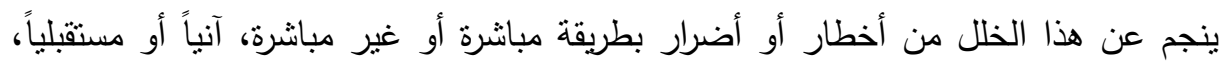

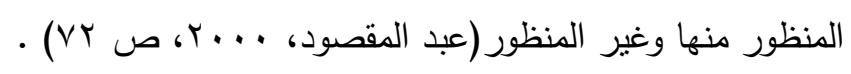
المؤسسات الإيوائية: Foster Houses: هي دار مجزة للأقامه الداخلية لإيواء الأطفال الدحرومين من الرعاية الأسرية بسبب الظروف الأسرية الصعبة، والتي تحول بينهم

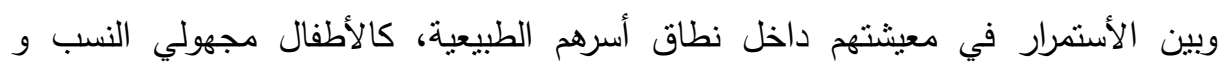

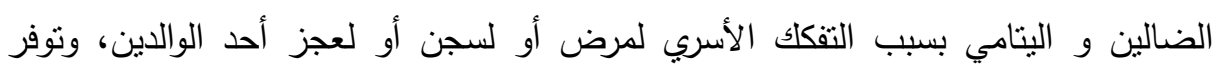

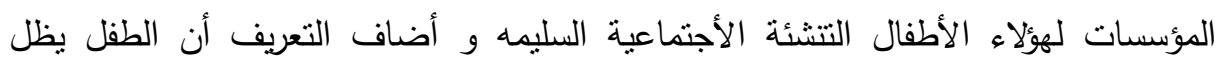

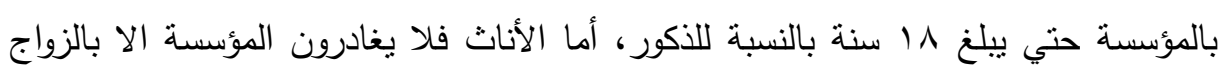

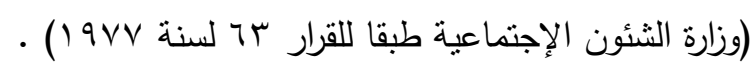

\section{الصراسايه المابرية}

دراسة(ياسمين عبدالمجيا، ب r): هدفت الدراسة الى التعرف علي المشكلات الأجتماعية للمقبلين علي الخروج من المؤسسات الإيوائية ومؤشرات للتعامل معها من منظور خدمه الفرد وتحديد أسباب المشكلات الأجنماعية للمقبلين علي الخروج من المؤسئسات الإيوائية للتوصل لمؤشرات من منظور الفرد للتعامل مع هذة المشكلات .

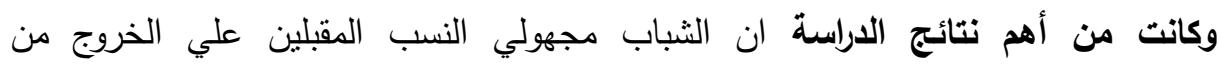

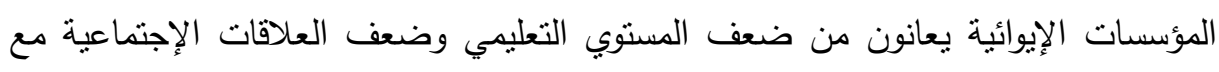
بعضهم البعض ومع المشرفين والأخصائيين الأجتماعيين والإدارة وادارة الثئون الأجتماعية. 


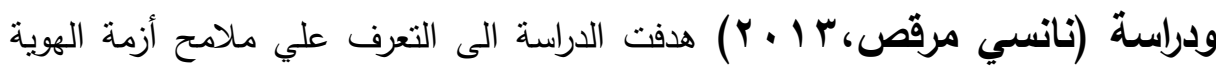
وعلاقتها بالبناء النفسي لدي المراهقين المقيمين في ظل الأسرة العادية والتعرف علي ملامح

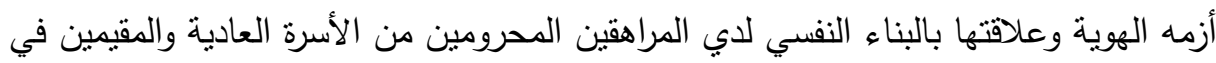

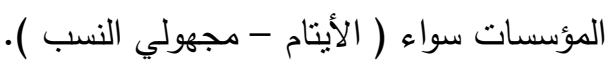
وكانت من أهم نتائج الدراسة ان المراهقين المقيمين مع أسرهم بنائهم النفسي أفضل من الناء المراهقين مجهولي النسب المقيمين بدور الأيتام، وان المراهقون المقيمين مع أسرهم بنائهم النفسي أفضل من المراهقين الأيتام المقيمين بدور الرعاية، وأن المراهقين الأيتام المقيمين بدور الأين الرعاية بنائهم النفسي أفضل من المراهقين مجهولي النسب المقيمين بدور الرعاية.

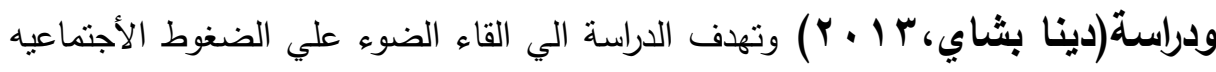
والفيزيقية فالضغوط الأجتماعيه بما تمنل علاقة أطفال الملاجئ بمن حولهم من الأخصائيين

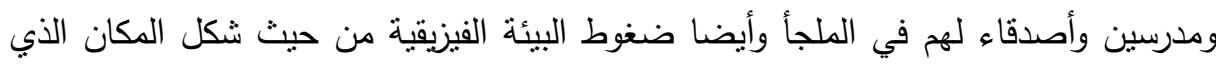

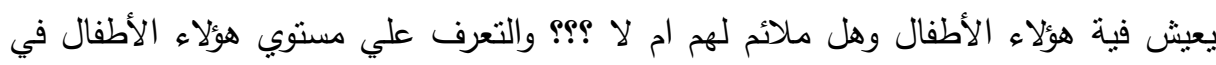

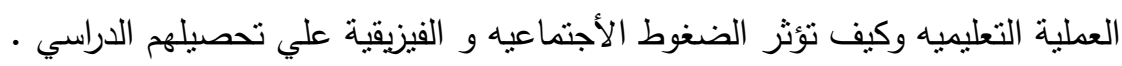

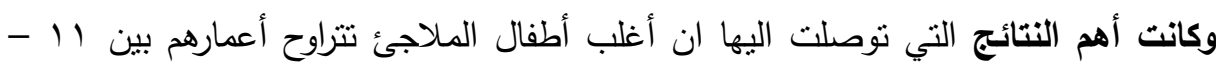

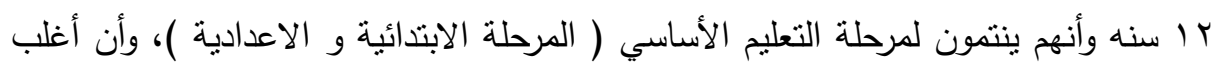

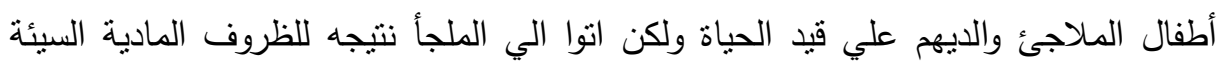

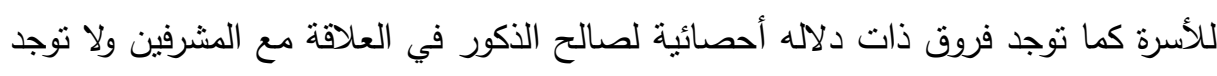

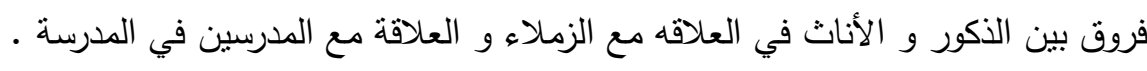
دراسة (سليفر SILVIER، 1991): هدفت الدراسة إلى تقييم البرامج المطبقة لنظام الإيواء فى خمس ولايات أمريكية، وطبقت الدراسة على خمس مراكز إيوائية فى خمس ولايات وهم :-

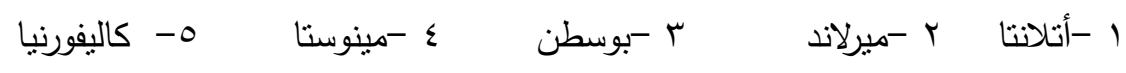

واستخدمت الدراسة أداه تقويم رئيسية لنظام الإيواء فى هذه الولايات، وتوصلت النتائج إلى ان

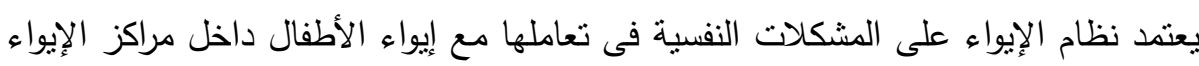

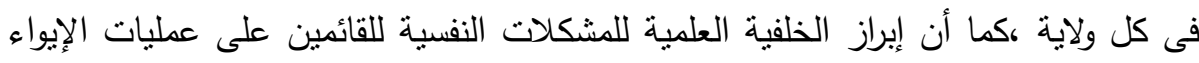
264

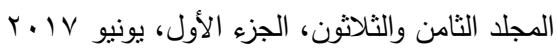


والتربية الأخلاقية داخل كل مركز من مراكز الإيواء فى كل الولايات التى شمها التقييم، كما

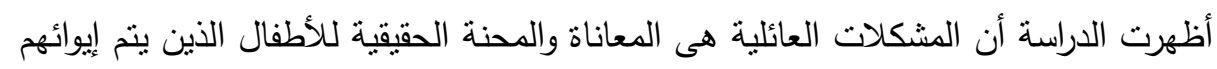

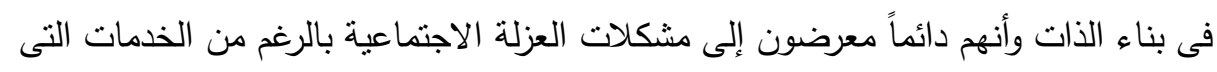
تقدم إليها داخل مراكز الإيواء.

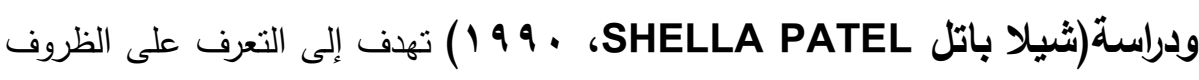

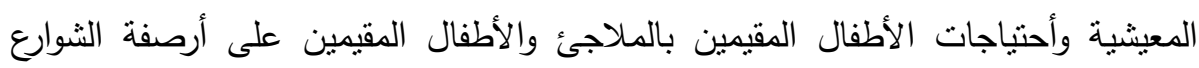

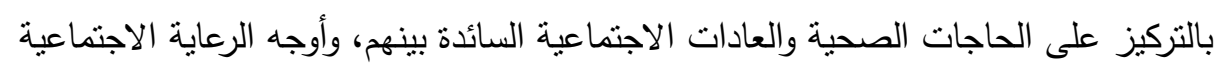

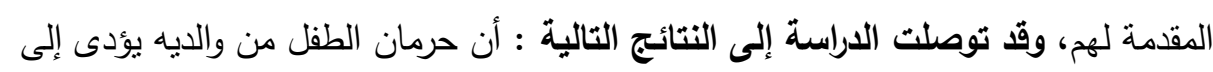

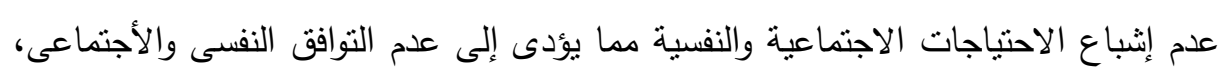

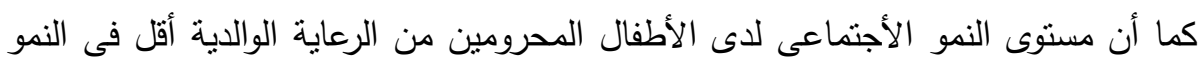

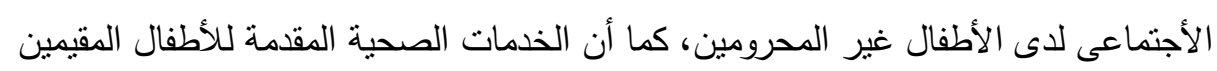
بالملاجئ والأطفال المقيمين على أرصفة الثوارع أقل من أحتياجاتهم العادية. ودراسةة(جلبرت Gilbert، 999 ( 99 ) هدفت الدراسة إلى فحص طبيعة المشكلات السلوكية

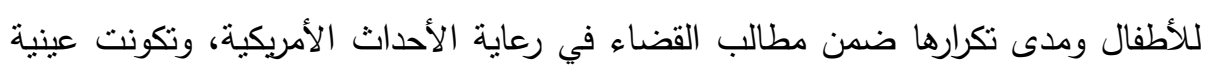

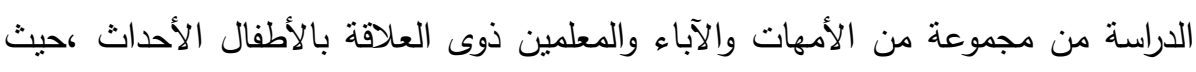
قاموا بتعبئة قائمة تدقيق خاصة بأنماط المشكلات السلوكية لأطفال الأحداث، وقد تم تقييم

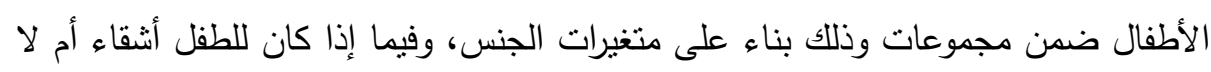

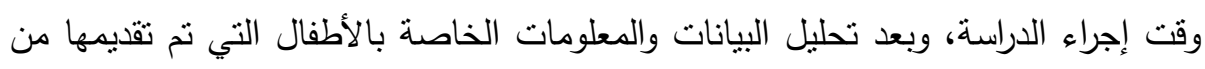

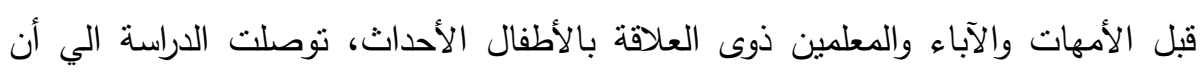

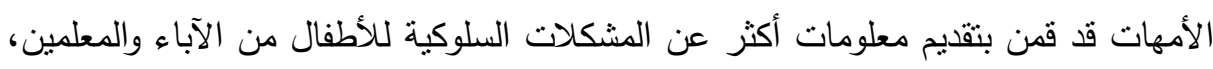

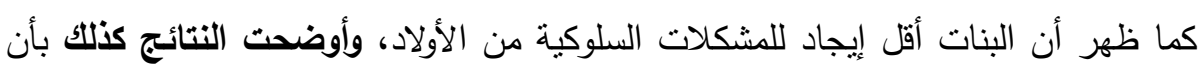

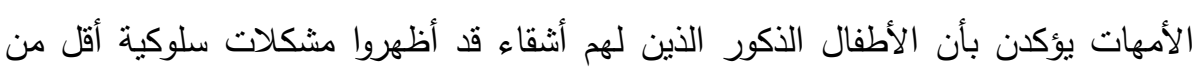

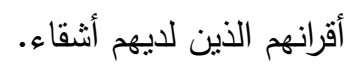




\section{الإسار اللنظليمه}

1 - نظرية الوصم الأجتماعي: وتري هذة النظرية ان الانحراف الأجتماعي ناتج عن مجموعه من الأفراد من المجتمع الي مجموعه أخري، فمثلا اذا قال الاوروبيون بأن افريقيا

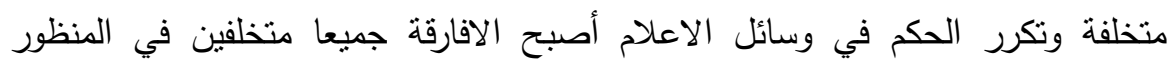

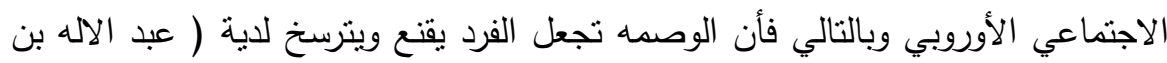

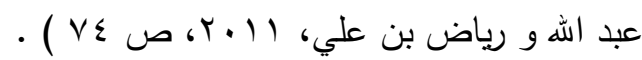
يري الباحثون ان هذة النظريه هي أقرب النظريات التي نتلائم مع بحثهم الراهن، علي

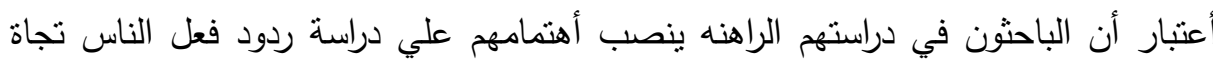

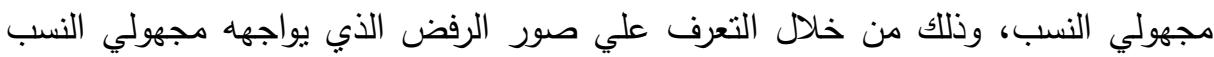
عند خروجهم من المؤسسات الايوائية وعند الزواج وإلصاق وصمه مجهولي النسب بهر، وهذا

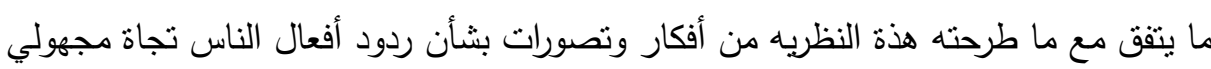
النسب.

r - نظرية النسق الأيكولوجي: أن النسق الايكولوجي مفهوماً جديداً لتحليل علاقه

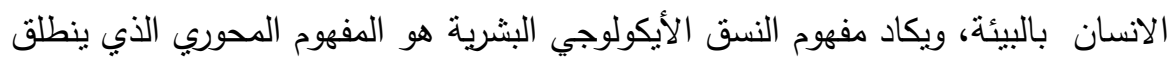

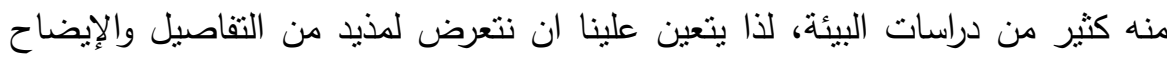

$$
\text { ويشير مفهوم النسق الايكولوجي: }
$$

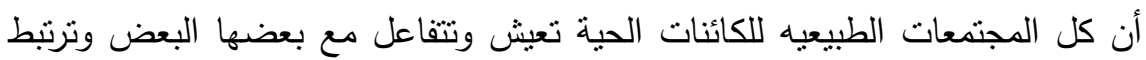
ارتباطاً وثيقا بييئاتها، ومن ثم يبدو من الملائم تصور طرفي العلاقه ( الكائنات الحية و بيئاتها

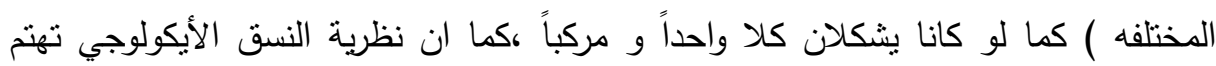

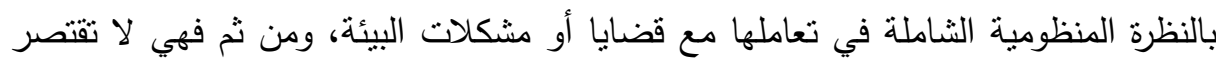

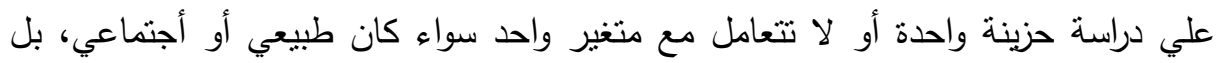

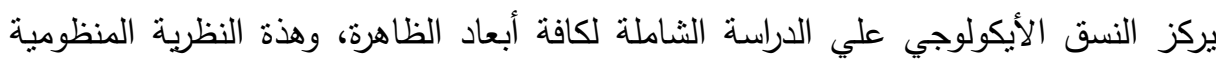

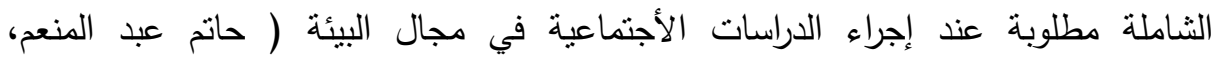

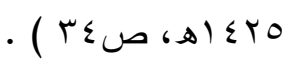




\section{الإجباءايت المنهجية}

المنهج المستخدم: سينم أستخدام المنهج الوصفى ويلى ذلك أستخدام المنهج النحليلى فى النى دراسة وتحليل البيانات الإحصائية الخاصة عن الثباب المقيمين في المؤسسات الإيوائية وما سيتم جمعة من خلال أستمارة الأستيان مع الأستعانة بالأساليب الكمية والأحصائية المناسبة.

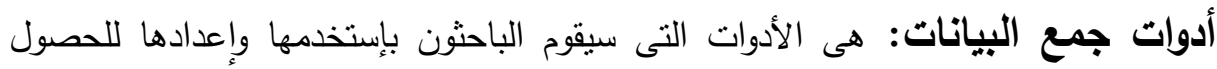

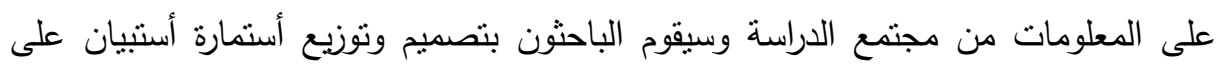

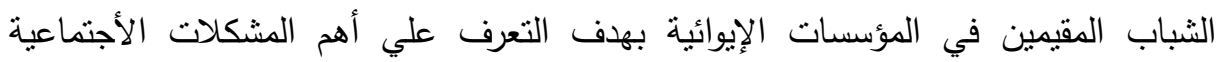
والفيزيقية التي تواجههم عند الزواج وكنلك الأعتماد على أسلوب الملاحظة والمقابلة الفيلة

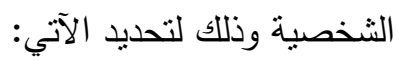

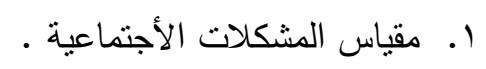

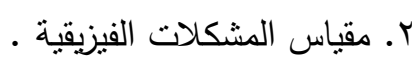

تم حساب ثبات وصدق المقاييس فكانت كالتالي:

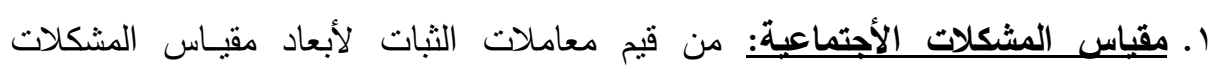

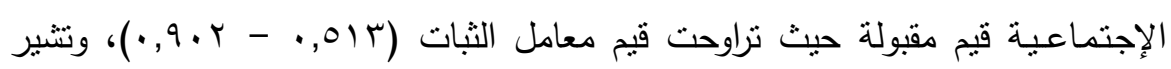

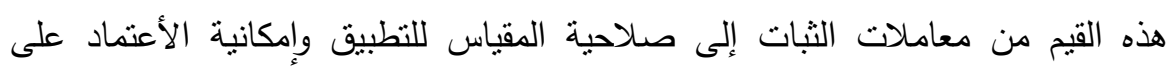

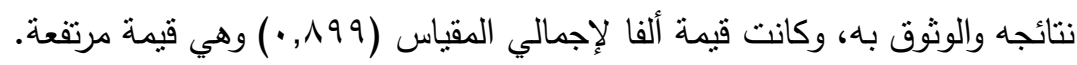

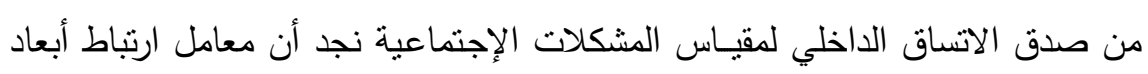

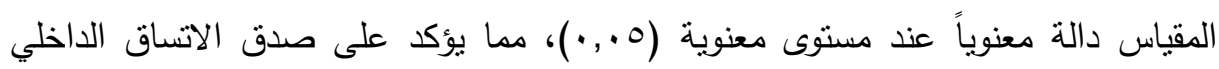

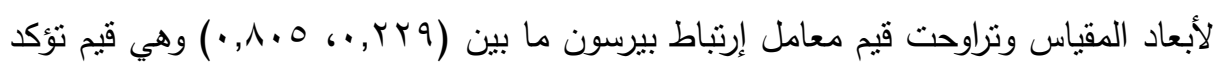
على صدق المقياس.

r. مقياس المشكلات الفيزيقية: من قيم معاملات الثبات لأبعاد مقيساس المشكلات الفيزيقية

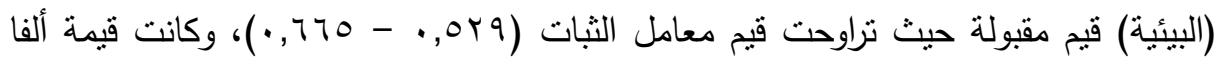

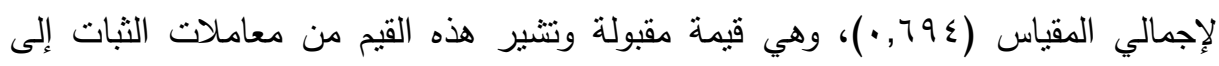

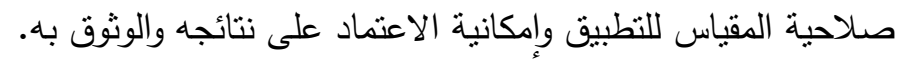


من صدق الاتساق الداخلي لمقيـاس المشكلات الفيزيقية نجد أن معامل ارتباط أبعاد

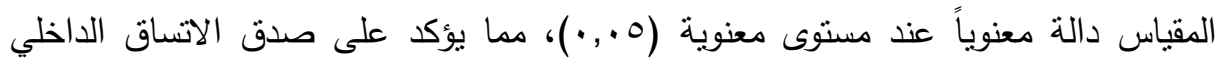

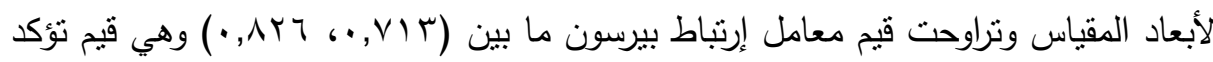
على صدق المقياس.

صدق التحكيم: نم عرض إستمارة الإستبيان الخاصة بتجميع بيانات هذا البحث في صورتها

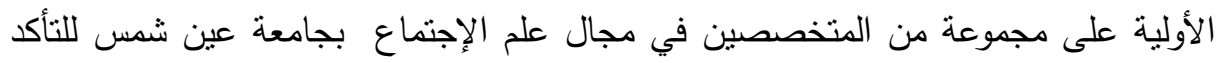

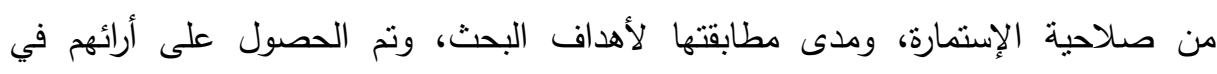

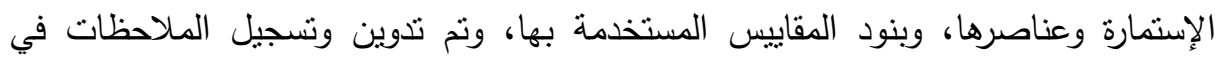

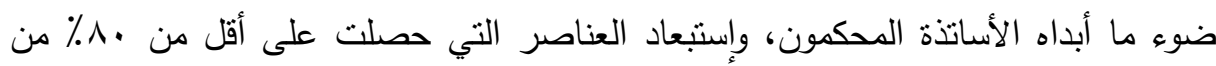
أرائهم، وبذا أصبحت الإستمارة صالحة لتجميع البيانات الميدانية في صورتها الحالية.

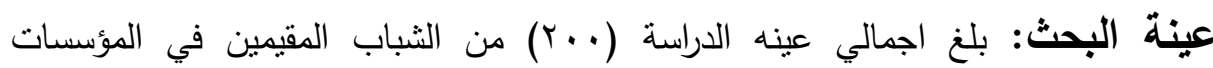

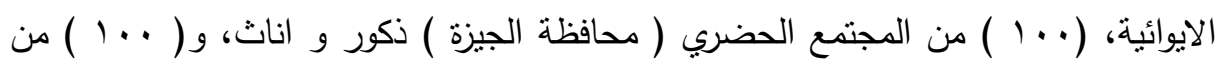

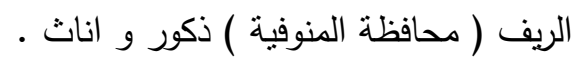

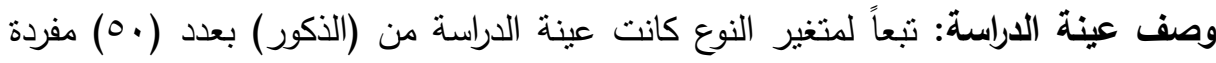

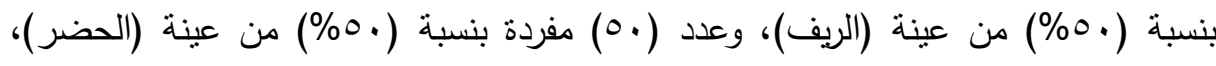

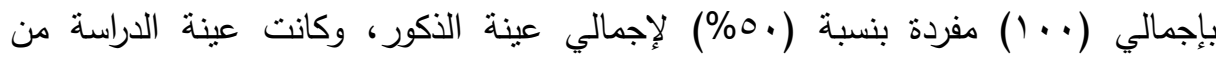

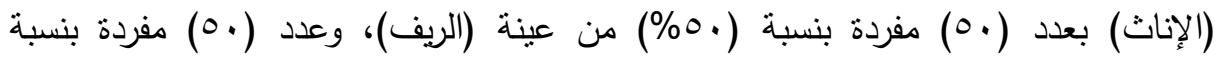

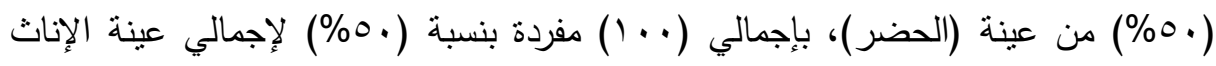
وكان متوسط سن الذكور لعينة (الريف) (19,1 (عام)، بينما كان متوسط سن الذبه الذكور لعينة

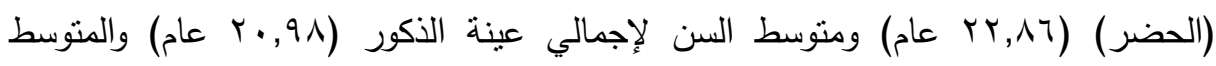

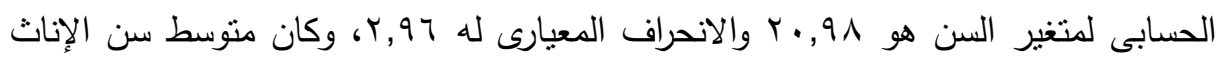

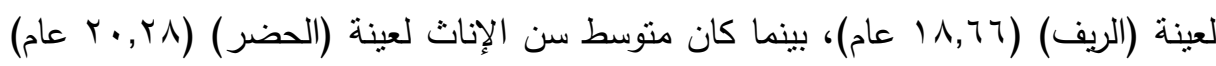

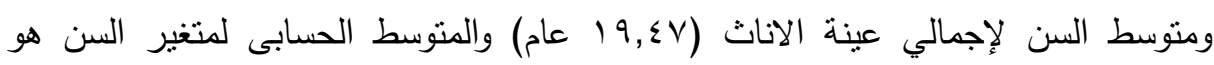

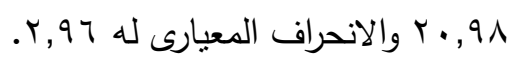




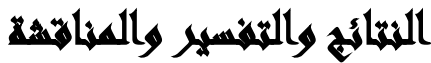

نتائج البحث ومناقثتها : يمكن عرض نتائج البحث على النحو التالي:

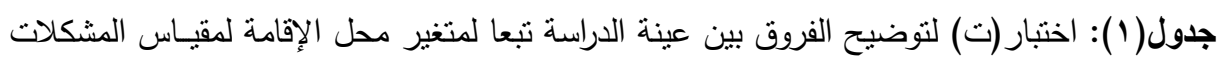

\begin{tabular}{|c|c|c|c|c|c|c|}
\hline \multirow[b]{2}{*}{ المعنوية } & \multirow[b]{2}{*}{ قيمة } & \multicolumn{2}{|c|}{ الحضر (ن=.0.0 } & \multicolumn{2}{|c|}{ الريف (ن= ، 0) } & \multirow[t]{2}{*}{ عينة الدراسة } \\
\hline & & الإنحرافي & المستوسط & الإلعصدراف & الحستوسي & \\
\hline$\cdot, \cdot r$ & $r, r \leq$. & $r, 07$ & $V, 07$ & $r, \varepsilon$. & $7, \varepsilon$. & حالزملاء دالاخل: العارقة \\
\hline$\cdot, \cdots$ & $\leqslant, 10 \leqslant$ & $1, V V$ & $7,1 \leq$ & $1, \leqslant 9$ & $\varepsilon, \vee \wedge$ & حور الثناني : العلاقة \\
\hline$\cdot, \ldots 7$ & $r, \wedge r \cdot$ & $r, \vee V$ & $\{, 0\}$ & r, ११ & $T, T \leq$ & جنماعى دالثالث: الاخصائية \\
\hline$\cdot, \cdots$ & $\leqslant, 9 r \leqslant$ & דוז, & $0, \cdot 7$ & $r, 17$ & $r, Y \wedge$ & حور الادارة داخلّ: الدار العلاقة \\
\hline$\cdot, \cdots$ & $0,9 \wedge r$ & $0,7 \varepsilon$ & rr,rr & \rceil,$\varepsilon$. & $17,1$. & اس المشُكلات \\
\hline
\end{tabular}

من الجدول السابق للفروق بين عينة الدراسة تبعا لمتغير محل الإقامة لمقياس المشكلات

الإجتماعية التي تواجه الثباب المقيمين في المؤسسات الإيوائية لعينة الذكور يتبين التالي: المحور الأول: العلاقة مع الزملاء داخل المؤسسات: يوجد فرق ذو دلاله إحصائية بين عينة الدراسة تبعا لمتغير محل الإقامة (الريف/الحضر) للعلاقة مع الزملاء داخل

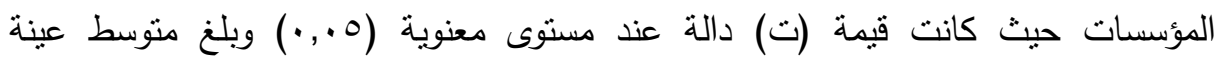

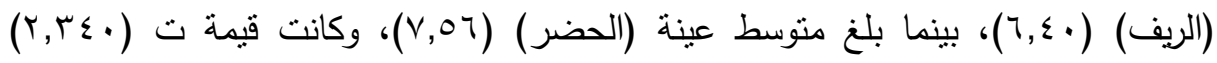
والدلالة المعنوية (r •, ·) وذللك لصالح عينة (الحضر ). المحور الثاني: العلاقة مع المشرفين داخل المؤسسات: يوجد فرق ذو دلاله إحصائية بين عينة الدراسة تبعا لمتغير محل الإقامة (الريف/الحضر) للعلاقة مع المشرفين

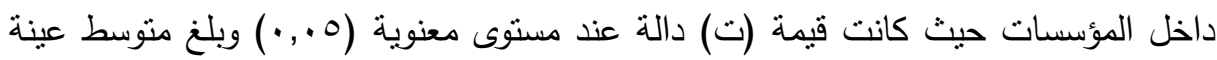




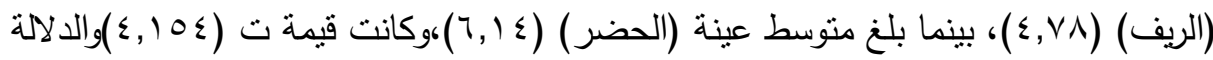

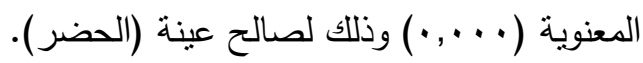
المحور الثالث: العلاقة مع الاخصائي الاجتماعي داخل المؤسسات: بوجد فرق ذو دلاله إحصائية بين عينة الدراسة تبعا لمتغير محل الإقامة (الريف/الحضر) للعلاقة مع

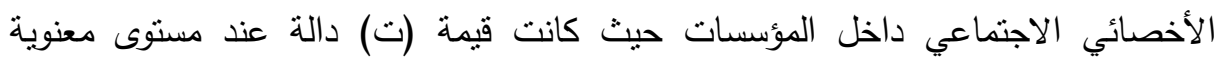

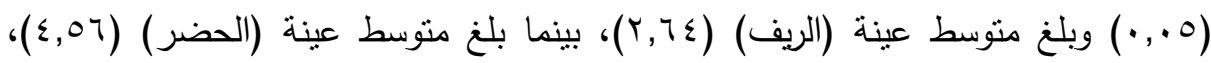

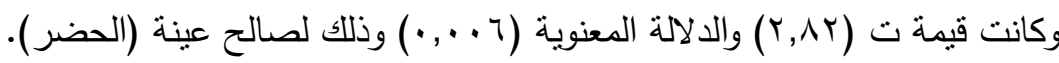
المحور الرابع: العلاقة مع الإدارة داخل المؤسسات: يوجد فرق ذو دلاله إحصائية بين عينة الدراسة تبعا لمتغير محل الإقامة (الريف/الحضر) للعلاقة مع الإدارة الاجتماعي

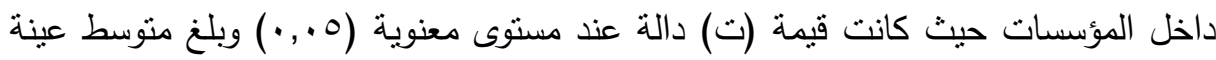

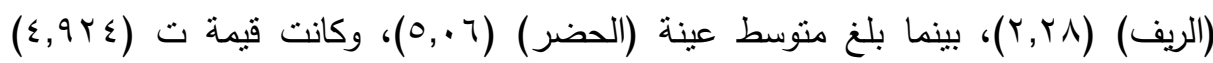
والدلالة المعنوية ( . . , • ) وذلك لصالح عينة (الحضر ). إجمالي مقيـاس المشكلات الإجتمـاعيـة: يوجد فرق ذو دلاله إحصائية بين عينة الدراسة

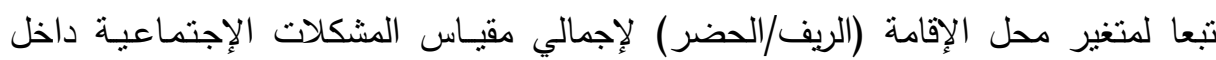

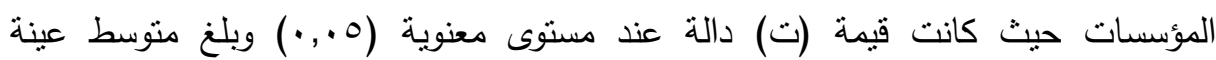

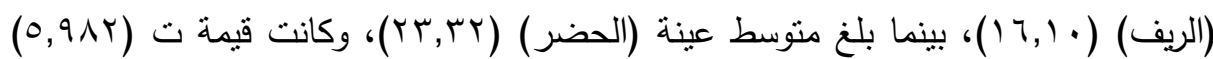

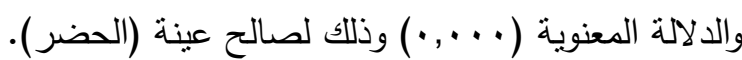

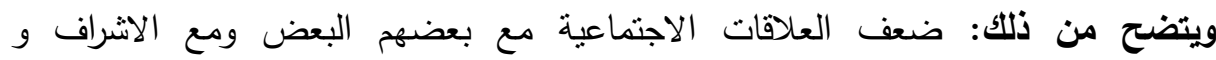

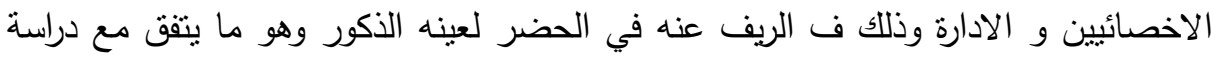

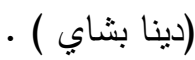


جدول(ץ): اختبار (ت) لتوضيح الفروق بين عينة الدراسة تبعا لمتغير محل الإقامة لمقيـاس المشكلات الفيزيقية (البيئية) التي تواجه الثباب المقيمين في المؤسسات الإيوائية

\begin{tabular}{|c|c|c|c|c|c|c|}
\hline \multirow[b]{3}{*}{ المعنوية } & \multirow[b]{3}{*}{ قيمة } & & & & \multicolumn{2}{|r|}{ لعينة الذكور } \\
\hline & & \multicolumn{2}{|c|}{ الحضر (ن=•) } & \multicolumn{2}{|c|}{ الريف (ن= ، 0) } & \multirow[t]{2}{*}{ عينة الدراسة } \\
\hline & & الإلمعرافي & الحسابي & الإنحراف & الحستوسي & \\
\hline$\cdot, 1$ & 1,700 & $r, I V$ & $V, r$. & r,or & $T, \sum Y$ & الأقامور \\
\hline$\cdot, \cdots r$ & $r, 111)$ & $r, \Sigma)$ & 0,1 . & 1,71 & $7, V 7$ & الحياتية النثاني: المهارات \\
\hline$\cdot, \wedge$ & $\cdot, r \circ q$ & $r, 00$ & 0,94 & $r, \cdot T$ & $7, \cdot \varepsilon$ & |الثالث: بيئة | \\
\hline$\cdot, \varepsilon$ & $7,1 \wedge 7$ & 7,11 & $1 \Lambda, Y Y$ & $0, r_{0}$ & $19, Y Y$ & زيقية مقياس| \\
\hline
\end{tabular}

من الجدول السابق للفروق بين عينة الدراسة تبعا لمتغير محل الإقامة لمقياس المشكلات الفيزيقية ( البيئية) التي تواجه الثباب المقيمين في المؤسسات الإيوائية لعينة الذكور يتبين التالي:

المحور الأول:أماكن الإقامة: لا يوجد فرق ذو دلاله إحصائية بين عينة الدراسة تبعا

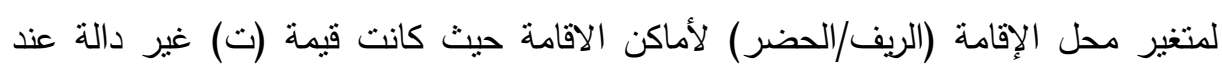

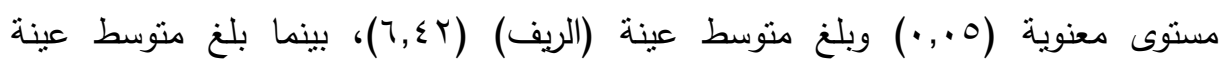

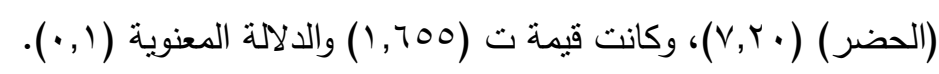

المحور الثاني:المهارات الحياتية: يوجد فرق ذو دلاله إحصائية بين عينة الدراسة تبعا

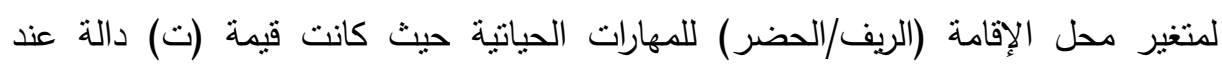

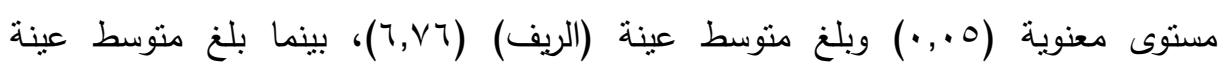

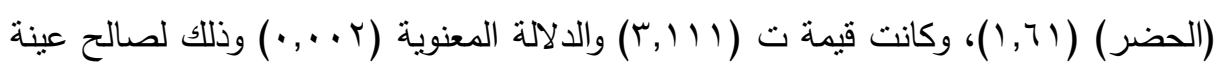


المحور الثالث: بيئة المسكن: لا يوجد فرق ذو دلاله إحصائية بين عينة الدراسة تبعا

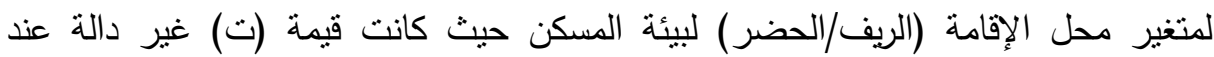
مستوى معنوية (0.,.) وبلغ متوسط عينة (الريف) (ع .,7)، بينما بلغ متوسط عينة

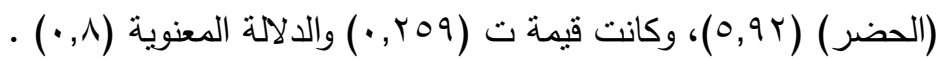
ويتضح من ذلك ضعف المهارات الحياتية والانشطة الثقافية المقدمه للذكور داخل المؤسسات

$$
\text { الإيوائية في الحضر عنها في الريف. }
$$

جدول(ץ): اختبار (ت) لتوضيح الفروق بين عينة الدراسة تبعا لمتغير محل الإقامة لمقيـاس لراس المشكلات الإجتماعية التي تواجه الثباب المقيمين في المؤسسات الإيوائية

ل لعينة الإناث

\begin{tabular}{|c|c|c|c|c|c|c|}
\hline الالالة & قيمة & $(0 .=0$ & الحضر & $(0,=$ & الريف (ن) & \\
\hline معنوية & $\ddot{ت}$ & الإلإنحرافي & المستبط & الإلمعياري & الحستوسط & ت الإجتماعية \\
\hline & $|T, r Y Y|$ & $r, r$. & $\Lambda, \Upsilon \wedge$ & 5,19 & 0,7 . & الدار الاول: العلاقة مع الزملاء \\
\hline$\cdot, \cdots V$ & $r, v, v$ & $1, V \varepsilon$ & $\varepsilon, 9 \leqslant$ & $1,9 \leq$ & $7, \cdots$ & ى اللدار العلاقة \\
\hline$\cdot, \mathrm{V}$ & $\cdot, \pi \circ N$ & $\varepsilon, 1 T$ & $0, \sum Y$ & $r, .0$ & 0,17 & 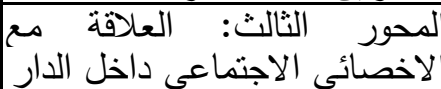 \\
\hline$\cdot, 7$ &., $0 \leq 0$ & $r, r q$ & $\varepsilon, 1 \wedge$ & $r, \wedge r$ & $\varepsilon, O r$ & سع الادارة| \\
\hline$\cdot, 9$ & $\cdot, 1 \wedge \mu$ & $\vee, \wedge \vee$ & $r Y, q Y$ & $7, \vee \wedge$ & Tr,T & |لمشكلات \\
\hline
\end{tabular}

من الجدول السابق للفروق بين عينة الدراسة تبعا لمتغير محل الإقامة لمقياس المشكلات الإجتماعية التي تواجه الثباب المقيمين في المؤسسات الإيوائية لعينة الاناث ينتين التالي: المحور الأول: العلاقة مع الزملاء داخل المؤسسات: يوجد فرق ذو دلاله إحصائية بين عينة الدراسة تبعا لمتغير محل الإقامة (الريف/الحضر) للعلاقة مع الزملاء داخل

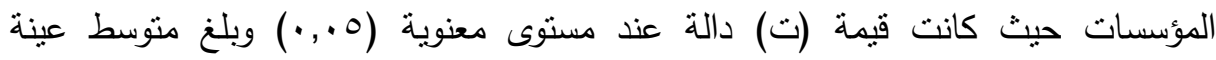

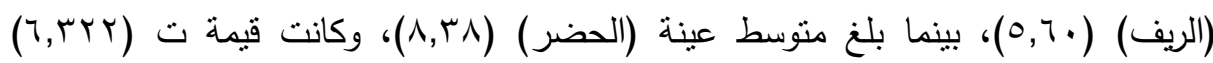
والدلالة المعنوية ( (..., . ) وذلك لصالح عينة (الحضر ). 
المحور الثاني: العلاقة مع المشرفين داخل المؤسسات: يوجد فرق ذو دلاله إحصائية بين عينة الدراسة تبعا لمتغير محل الإقامة (الريف/الحضر) للعلاقة مع المشرفين

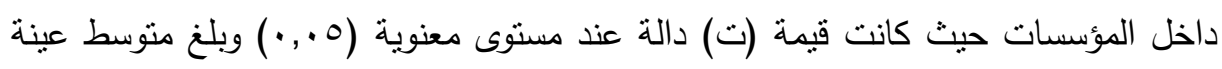

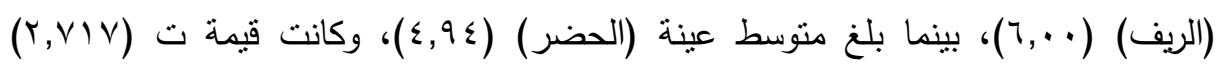
والدلالة المعنوية (v · , , ·) وذلك لصالح عينة (الريف).

المحور الثالث: العلاقة مع الاخصائي الاجتماعي داخل المؤسسات: لا يوجد فرق

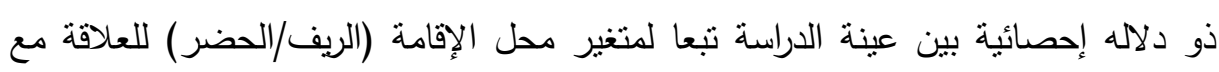

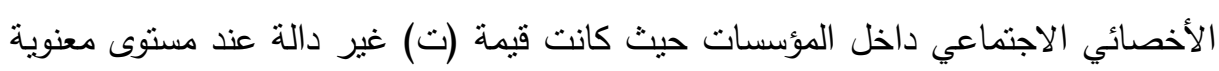

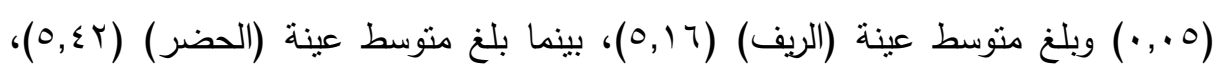

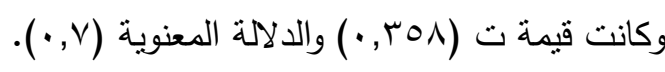
المحور الرابع: العلاقة مع الإدارة داخل المؤسسات: لا يوجد فرق ذو دلاله إحصائية بين عينة الدراسة تبعا لمتغير محل الإقامة (الريف/الحضر) للعلاقة مع الإدارة داخل

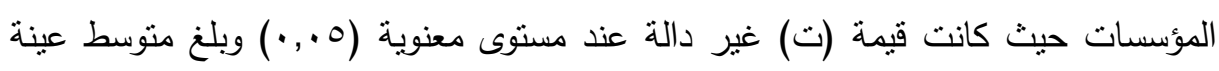

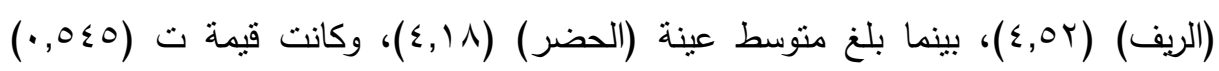

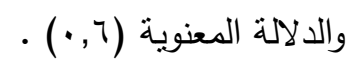
إجمالي مقيـاس المشكلات الإجتمـاعيـة: لا يوجد فرق ذو دلاله إحصائية بين عينة الدراسة تبعا لمتغير محل الإقامة (الريف/الحضر) لإجمالي مقيـاس المشكلات الإجتماعيـة داخل

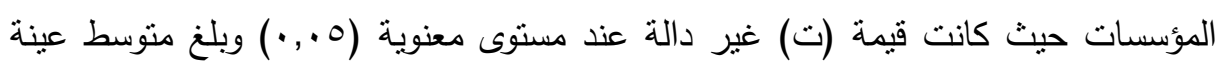

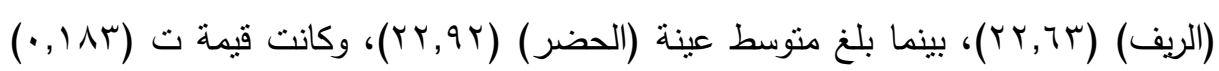
والدلالة المعنوية (9 ( •). ويتضح من ذلك ضعف العلاقات الأجتماعية مع بعضهم البعض ومع الأشراف والأخصائيين والادارة وذلك في الريف والحضر لعينه الأناث وهو ما يتفق مع دراسة (ياسمين عبد المجيد ). 
جدول(؛): اختبار (ت) لتوضيح الفروق بين عينة الدراسة تبعا لمتغير محل الإقامة لمقبـاس المشكلات الفيزيقية (البيئية) التي تواجة الثباب المقيمين في المؤسسات الإيوائية

$$
\text { لعينة الإناث }
$$

\begin{tabular}{|c|c|c|c|c|c|c|}
\hline \multirow{2}{*}{ المعنوية } & \multirow[b]{2}{*}{ قيمة } & \multicolumn{2}{|c|}{ الحضر (ن=.0) } & \multicolumn{2}{|c|}{ الريف (ن= .0) } & \multirow{2}{*}{ مقياس المشكلاتة الإلفيزيقية } \\
\hline & & الألمعياري & الحستابي & الإمعياري & الحستابي & \\
\hline & $r, \wedge 90$ & $r, \cdot 1$ & $\wedge, \wedge \uparrow$ & $r, \Gamma \varepsilon$ & $V, 17$ & يحور الأول: \\
\hline$\cdot, \varepsilon$ & $\cdot, \wedge) \cdot$ & $r, I V$ & $\wedge, 0$. & $r, \cdot r$ & $\wedge, \wedge \varepsilon$ & المهارات \\
\hline,,$\ldots 7$ & $Y, V \wedge Y$ & 1,00 & $\vee, 0 \wedge$ & $1, \Lambda Y$ & $7,7 \varepsilon$ & الثالث: بيئة المسكن \\
\hline,$\cdots \wedge$ & $r, 79 r$ & 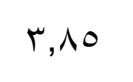 & $T \leq, 9 \varepsilon$ & $\varepsilon, 77$ & YY,T & المشكلات \\
\hline
\end{tabular}

من الجدول السابق للفروق بين عينة الدراسة تبعا لمتغير محل الإقامة لمقياس المشكلات الفيزيقية(البيئية) التي نواجه الثباب المقيمين في المؤسسات الإيوائية لعينة الاناث يتبين التالي: المحور الأول:أماكن الأقامة: يوجد فرق ذو دلاله إحصائية بين عينة الدراسة تبعا لمتغير محل الإقامة (الريف/الحضر) لأماكن الأقامة حيث كانت قيمة (ت) دالة عند مسنوى معنوية

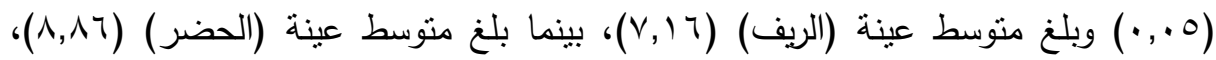

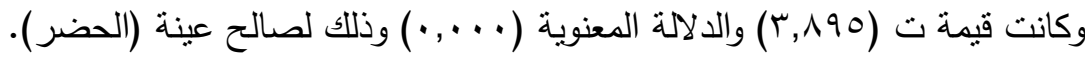
المحور الثاني:المهارات الحياتية: لا يوجد فرق ذو دلاله إحصائية بين عينة الدراسة

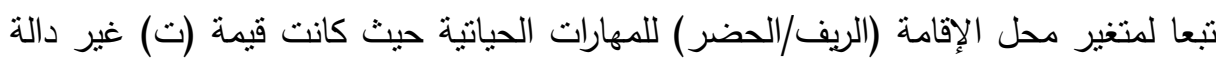

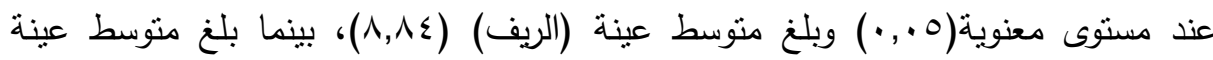

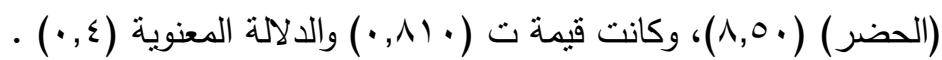
المحور الثالث: بيئة المسكن: يوجد فرق ذو دلاله إحصائية بين عينة الدراسة تبعا لمتغير محل الإقامة (الريف/الحضر) لبيئة المسكن حيث كانت قيمة (ت) دالة عند مستوى درى دله 
معنوية (0., •) وبلغ منوسط عينة (الريف) (\&,7,7)، بينما بلغ متوسط عينة (الحضر)

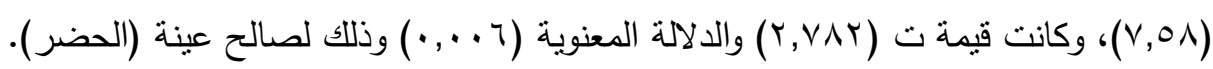

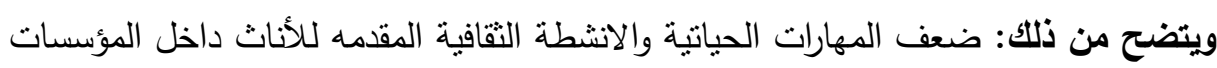

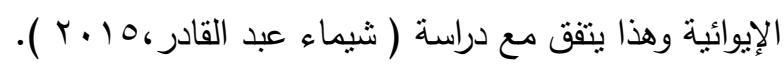

جدول(ه): العلاقة الارتباطية بين مقيـاس المشكلات الإجتماعية ومقياس المشكلات الفيزيقية

لعينة الريف

\begin{tabular}{|c|c|c|c|c|c|}
\hline 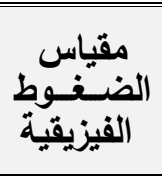 & الثائة الثمور: & المحورالثانى: المهارية: & ألأول: الأولت: & & \\
\hline **,Y. & + & $\cdot, \cdot 7$ & **., 199 & معامل الارتباط & \multirow{2}{*}{ العلاقة دع الزملاء الأدل } \\
\hline$\cdot, \cdot \varepsilon$ & 1 & $\cdot, 00 \pi$ & $\cdot, \cdots$ & |الدلالة المعنوية & \\
\hline$\cdot, 19 \mathrm{~V}$ & 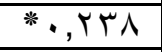 & $\cdot, r$ & $\cdot, \cdot 7$ & |معامل الإنباط & \multirow{2}{*}{ العلاقة دح الثشرئين الثارفين } \\
\hline$\cdot, \cdot 7$ & $\cdot, \cdot r T$ & $\cdot, .01$ & $\cdot, 0 \vee 1$ & |الدلالة المعنوية & \\
\hline$* * \cdot, T V T$ & $* *, r) V$ & $* *, 779$ & ***, IYr & معامل الارتباط & \multirow{2}{*}{ الاحتمع الاخصائئي :العلاقة داخلى الدار } \\
\hline - & $\cdot, \cdots 1$ & $\cdot, \cdots$ & $\cdot, \cdots$ & |الدلالة المعنوية & \\
\hline$* * 09$. & $* *, r 79$ & $* *, Y \cdot r$ & $* *, 0 \leqslant$. & معامل الارتباط & \multirow{2}{*}{ العلاقة مع اللادادارة } \\
\hline$\cdot, \ldots$ & $\cdot, \cdots V$ & $\cdot, \cdots$ & $\cdot, \cdots$ & الدلالة المعنوية & \\
\hline$* * 999$. & $* \cdot, r \cdot \varepsilon$ & $* *, 0 \wedge \varepsilon$ & $* *, 097$ & معامل الارتباط & \multirow{2}{*}{ مقيـاس الإجتمـاعبـــاتلات } \\
\hline$\cdot, \ldots$ & $\cdot, \cdots r$ & $\cdot, \ldots$ & $\cdot, \ldots$ & |الدلالة المعنوية & \\
\hline
\end{tabular}

المحور الاول:العلاقة مع الزملاء داخل الدار: توجد علاقة ارتباطية ذات دلاله معنوية بين العلاقة مع الزملاء داخل الدار ومقياس الضغوط الفيزيقية لعينة الريف حيث بلغت قيم الرئ

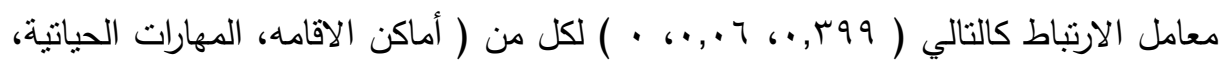

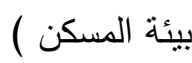
المحور الثاني: العلاقة مع المشرفين داخل الدار: توجد علاقة ارتباطية ذات دلاله معنوية بين العلاقة مع المشرفين داخل الدار لعينة الريف حيث بلغت قيم معامل الارتباط كالتالي: معند 
المحور الثالث: العلاقة مع الاخصائي الاجتماعي داخل الدار: توجد علاقة

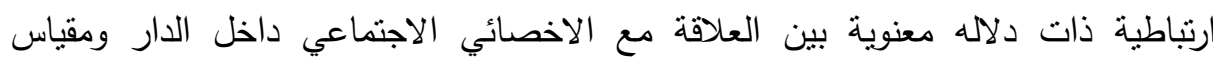

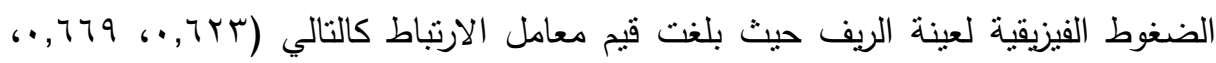

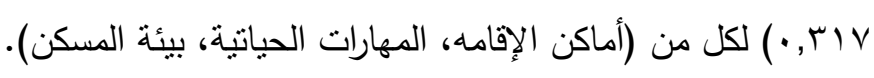

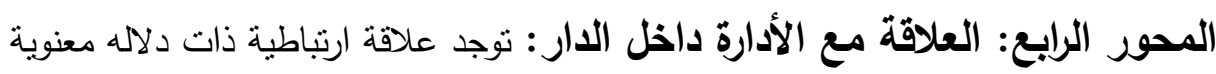

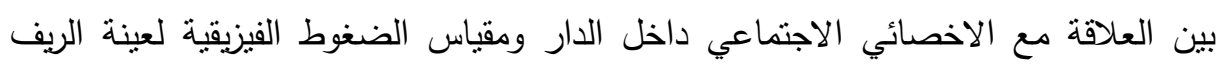

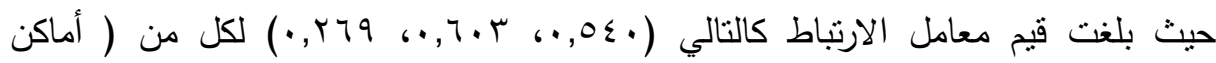

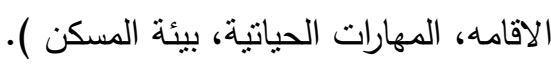

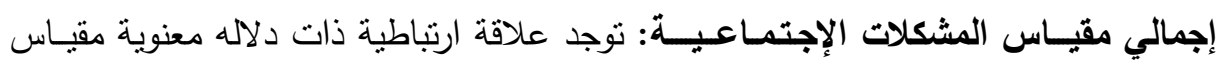

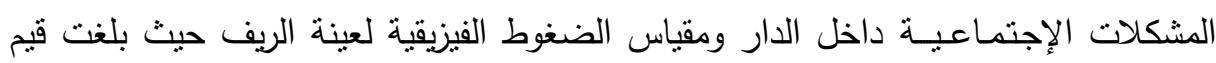

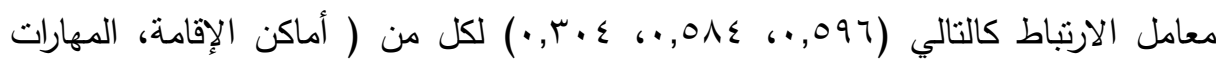
الحياتية، بيئة المسكن ). ويتضح لنا من ذلك انه توجد علاقة ارتباطية بين المشكلات الاجتماعية للشباب المقيمين في بئه

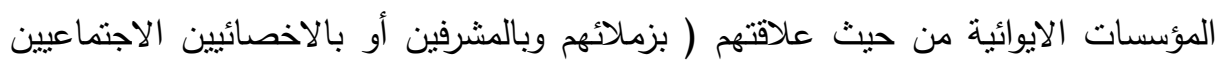

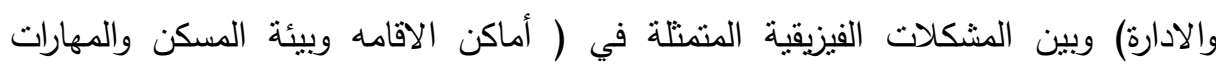

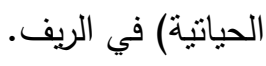


جدول(7): العلاقة الارتباطية بين مقياس المشكلات الإجتماعية ومقياس المشكلات الفيزيقية

\begin{tabular}{|c|c|c|c|c|c|}
\hline المشئكلات & الثالث : ليئة & المحورالثانى: المهاراتية & الألماكن: الأقامنة & \multicolumn{2}{|c|}{ يبه الحصر } \\
\hline$\cdot, .09-$ & $9,1 Y \cdot-$ & $\cdot, \cdot, I Y$ & $\cdot, .01-$ & معامل الارتباط & المحور الا \\
\hline$\cdot, 7$ & $\cdot, r$ & $\cdot, 9$ & $\cdot, 7$ & الدلالة المعنوية & \\
\hline **, YYV- & $\cdot, \cdot, \wedge \wedge-$ & $\cdot, 17,-$ & ***, Yq7- & معامل الارتباط & المحور الثانى : \\
\hline$\cdot, \cdot r$ & $\cdot, \varepsilon$ & $\cdot, 1$ & $\cdot, \cdot r$ & الدلالة المعنوية & المشرفين داخل \\
\hline ***, ro7 & **, ror & ***,,$\Gamma \Psi \varepsilon$ & $\cdot, I Y Y$ & معامل الارنباط & المحور الثالث : \\
\hline$\cdot, \cdots$ & $\cdot, \cdots$ & $\cdot, \cdots 1$ & $\cdot, r$ & الدلالة المعنوية & \\
\hline$* *, r \leq \varepsilon$ & $* *, \Sigma \backslash \Gamma$ & $* *, r \leq r$ & $\cdot, \cdot r$ & معامل الارتباط & اليحور الرابع : \\
\hline$\cdot, \cdots$ & $\cdot, \cdots$ & $\cdot, \cdots$ & $\cdot, \wedge \leq Y$ & الدلالة المعنوية & الادارة داخل \\
\hline$* *, 99$. & $* *, r \leq \Sigma$ & ***, rY O & $\cdot, \cdot, \cdot \cdot-$ & معامل الارتباط & مقيـاس \\
\hline$\cdot, \cdots$ & $\cdot, \cdots$ & $\cdot, \cdots$ & $\cdot, \wedge$ & الدلالة المعنوية & الإجتمـاعبـــة \\
\hline
\end{tabular}

المحور الاول:العلاقة مع الزملاء داخل الدار: نوجد علاقة ارتباطية ذات دلاله معنوية بين العلاقة مع الزملاء داخل الدار ومقياس الضغوط الفيزيقية لعينة الحضر حيث بلغت قيم

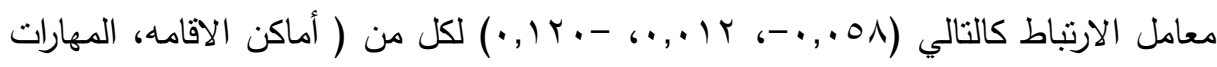

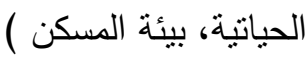
المحور الثاني: العلاقة مع المشرفين داخل الدار:توجد علاقة ارتباطية ذات دلاله معنوية بين العلاقة مع المشرفين داخل الدار لعينة الحضر حيث بلغت قيم معامل الارتباط

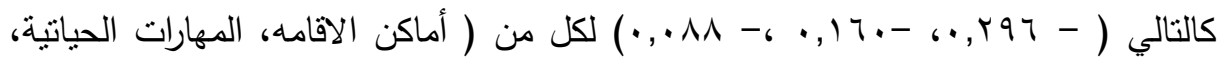
بيئة المسكن ) 
المحور الثالث:العلاقة مع الاخصائي الاجتماعي داخل الدار: نوجد علاقة ارتباطية ذات دلاله معنوية بين العلاقة مع المشرفين داخل الدار لعينة الحضر حيث بلغت قيم معامل

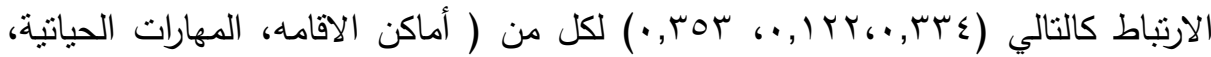

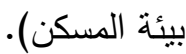
المحور الرابع :العلاقة مع الأدارة داخل الدار: نوجد علاقة ارتباطية ذات دلاله معنوية بين العلاقة مع المشرفين داخل الدار لعينة الحضر حيث بلغت قيم معامل الارتباط كالتالي

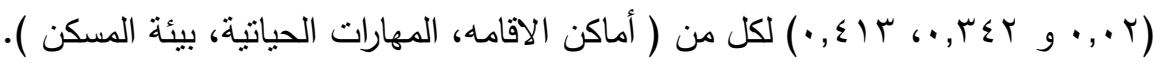

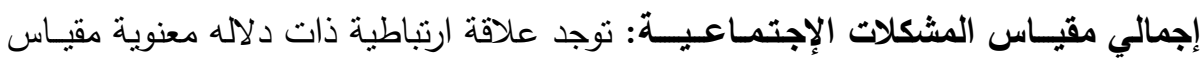

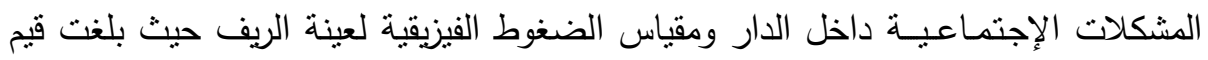

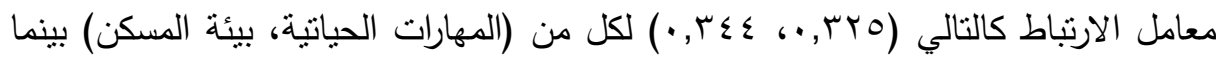
لم يكن هناك علاقة ارتباطية ذات دلاله معنوية بين مقيـاس المشكلات الإجتمـاعبــة داخل الدار وأماكن الاقامه معامل الارتباط كالتالي (- •. •. ••). ويتضح لنا من ذلك انه نوجد علاقة ارتباطية بين المشكلات الاجتماعية للشباب المقيمين في المؤسسات الايوائية من حيث علاقتهم ( بزملائهم أو بالمشرفين أو بالاخصائيين الاجتماعيين

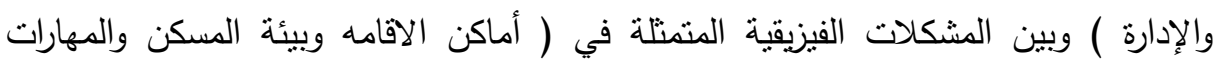

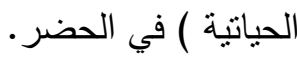

\section{التحوصياهت}

(1) يجب تحرى الدقة بقدر الإمكان عند اختيار الذين يتولون مسئولية رعاية المقيمين في

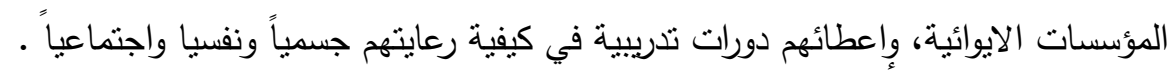

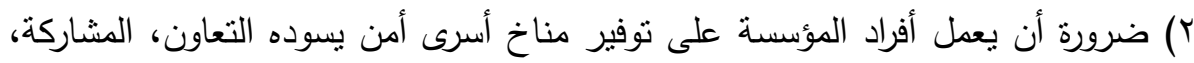

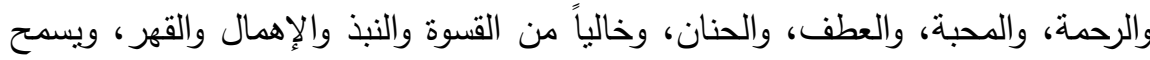

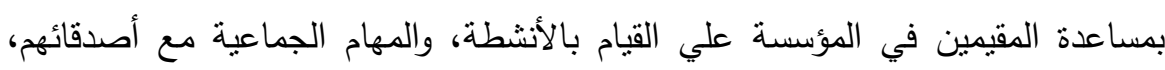


حتى يتاح لهم فرص التفاعل الجيد معهم، وكذللك توفير جو من المساندة الاجتماعية لهم

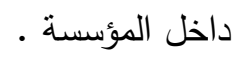

r) العمل علي نوفير دورات تدريبية وندوات للمقيمين في المؤسسات الإيوائية لتوعيتهم

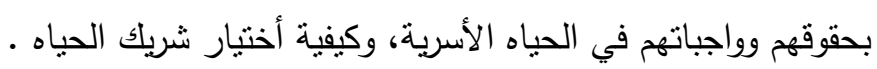

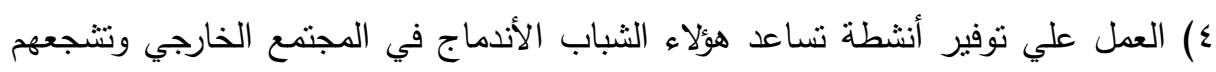
علي العمل و تحمل المسئولية .

0) توعية المجتمع لهذة الفئة ولدور المؤسسات في تربية الأيتام وخلق جو من التتافس بين

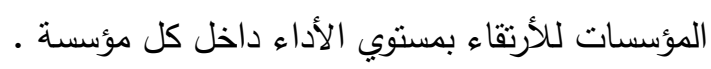

\section{rall}

إدارة الأسرة والطفولة، القرار الوزاري رقم سج لسنة ، I9VV

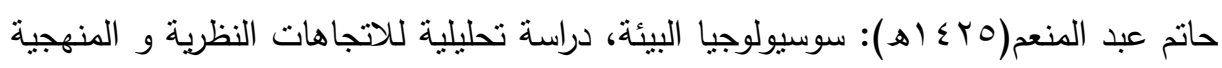

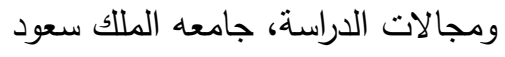

حامد زهران( • 99 ()): علم نفس النمو، الطبعة الخامسة، القاهرة

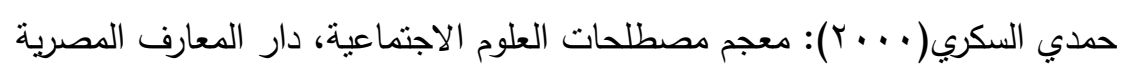
خليل ميخائيل معوض( 999 (1): علم النفس الاجتماعي، الاسكندرية، دار الفكر الاجتماعي.

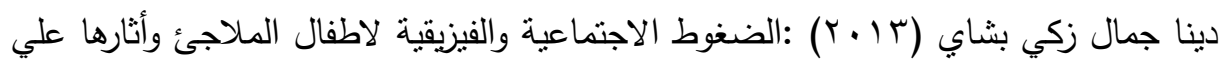

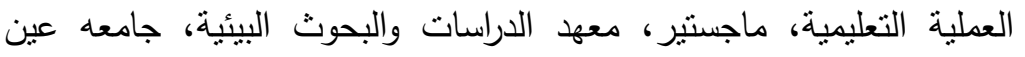

\section{شمس العملة الم}

رمضان محمد القذافي(997(1): اساسيات الصحة النفسية، القاهرة، المكتب الجامعي الحديث

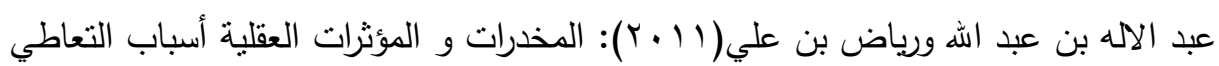

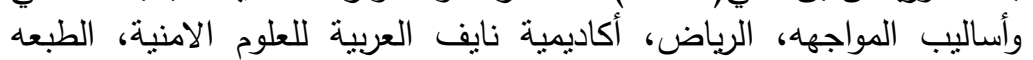

$$
\text { الاولي }
$$

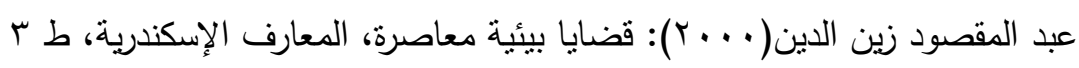

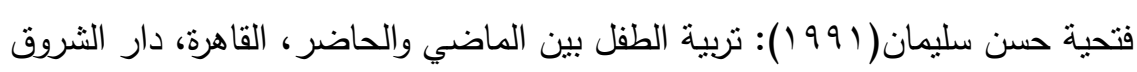

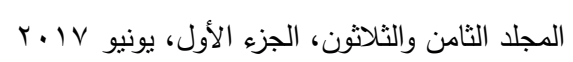




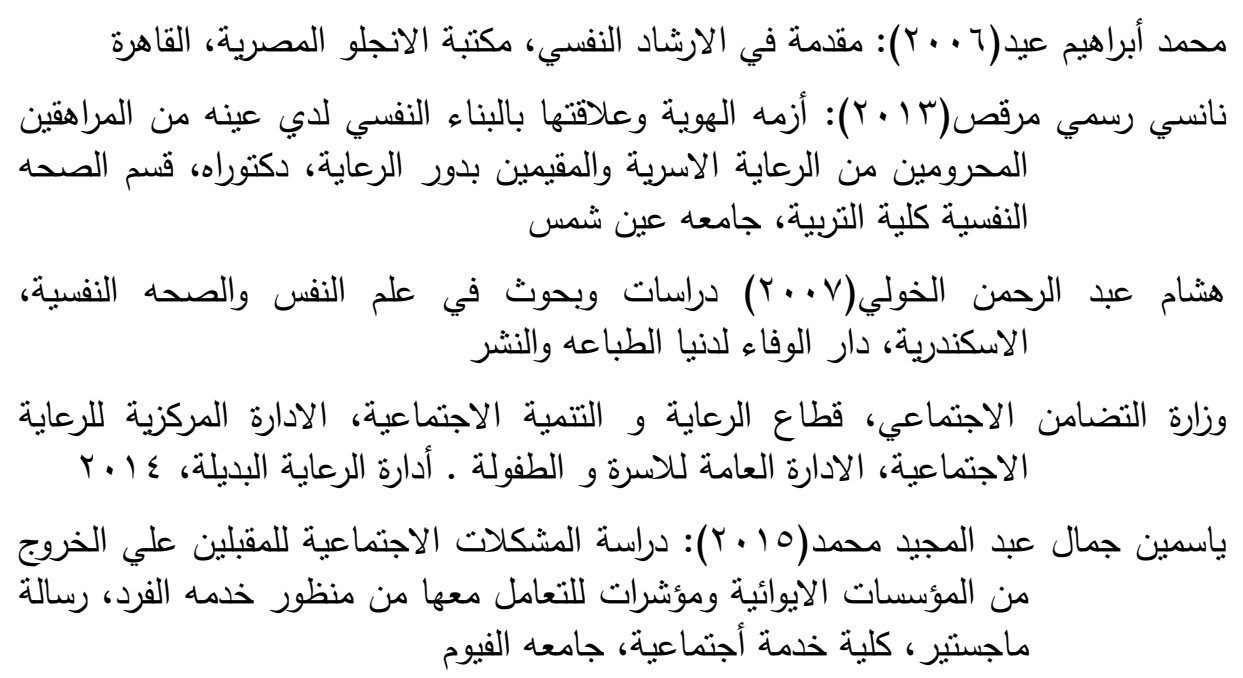

Shella Patel (1990): Street children, Hotel boys and children of parents

Dwellers and construction workers in bormbay- How they meet their danily enviroment and urbanizakion, J. Article, Vol. (2) .

Silver, (1991): Evaluating the applied programs in the sheltering system New Yourk, Vol. (51). Pp. 245 - 247.

Gilbert, a Michele, (1999). "behavioralproplems of children involved in custody legislation the byffer effect associated with having siblings master abstract international". vol 37, no (4),p 1258 . 
حاتم عبد المنعم أحمد وآخرون

\title{
THE SOCIAL AND PHYSICAL PROBLEMS FACING YOUTH IN FOSTER HOUSES AT MARRIAGE \\ A COMPARATIVE STUDY BETWEEN MALES AND FEMALES IN URBAN AND RURAL AREAS
}

\author{
Ahmed, H. A. ${ }^{(1)}$; Hani, A. F. ${ }^{(1)}$ and Ibrahim, Doha, S. A. \\ 1) Environmental Studies and Research Institute, Ain Shams University
}

\begin{abstract}
The current study aimed at identifying the most important social issues facing youth living in residential institutions upon marriage and identify the most important physical problems facing youth living in residential institutions upon marriage and therefore the importance of this study lies in the fact that there are some features that distinguish these residential institutions depositors attributes such as the sense of stigma and shame and introverted and imaginative and tension and between legitimate children and expand within their families and to those who say that children are not immigrants often become perverse result status Which impacts negatively on their development and their upbringing, they are prone to health and education and social neglect and emotional, of unknown parentage is looking for knowledge of this symptom and what is his role in life, and has to be situated and what a husband or a father.

Analytic study is using sample social survey methodology, and chose a random sample consisting of (200) of young people living in residential institutions, (100) urban community (Giza), male and female, and (100) from the countryside (almnofia County) male and female researchers observation and interview sample using questionnaire and after collecting the data are encoded and statistically analyzed using statistical analysis software SPSS.
\end{abstract}

The study pointed to a number of conclusions :- Poor social relationships among the evaluators within the residential and with

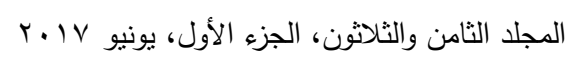


supervisors and social workers and management in rural and urban areas and to the lack of professional staff working with children in institutions.

The search has recommended that the members of the institution to provide a secure prisoners cooperation, sharing, compassion, love, kindness, tenderness, and free from cruelty and abandonment and neglect and oppression, and assist residents in the institution to undertake the activities and tasks with their friends, so they have good opportunities for interaction with them, as well as provide an atmosphere of social support for them within the enterprise. 